\title{
Evidence of increased prevalence of Multiple Sclerosis: A Population-Based Study of Tehran Registry, 1999-2018
}

\author{
Amir Almasi-Hashiani \\ Arak University of Medical Sciences \\ Mohammad Ali Sahraian \\ Tehran University of Medical Sciences \\ Sharareh Eskandarieh ( $\nabla$ sh_eskandarieh@yahoo.com ) \\ Tehran University of Medical Sciences
}

Research article

Keywords: Multiple Sclerosis, Prevalence, Epidemiology, Tehran, Iran

Posted Date: January 20th, 2020

DOI: https://doi.org/10.21203/rs.2.21220/v1

License: (c) (i) This work is licensed under a Creative Commons Attribution 4.0 International License. Read Full License 


\section{Abstract}

Background: The epidemiological characteristics of Multiple Sclerosis (MS) in various studies have been investigated and studies suggested that there is a different geographic disparity worldwide. The present study conducted to investigate the longitudinal prevalence of MS in Tehran, Iran.

Methods: The population-based study was conducted in Tehran, the capital of Iran from 1999 to 2018 based on the annual report data through the Iranian MS Society (IMSS) registry system. The age-standardized and crude prevalence proportions were estimated by applicant of population data, established from the Statistical Centre of Iran.

Results: Totally 21,580 MS cases were registered and included in the analysis. Out of them, $24.99 \%(5,393$ cases) was male and $75.01 \%(16,187$ cases) was female. The mean age of MS onset was 28.8 years (S.D: 8.7). The age standardized prevalence proportion (ASP) of MS ranged from 73.7 (95\%Cl: $72.1-75.2)$ in 2006 to 137.6 (95\% Cl: 135.7-139.5) per 100,000 in 2018. The MS ASP- was estimated 54.1 (95\% Cl: 53.6-54.6) among males and 174.5 (95\%Cl: $173.6-$ 175.4) per 100,000 among females. The age standardized female to male ratio of MS in study period was 3.03.

Conclusion: Our finding suggested that the prevalence of MS in Tehran province is relatively high and the disease occurrence is more common in the under-40 age group than in the older ones. As in the rest of the world, the prevalence of the MS was higher in women, and the female to male sex ratio was 3.03 in our study.

\section{Background}

Multiple sclerosis (MS) is considered as a chronic autoimmune neurological disease [1] which is known as the most prevalent inflammatory neuroimmunological disorder among young adults [2, 3]. MS usually occurs in young people and occurs more often before the age of 40 and in women [4, 5]. Due to the onset of a disease at an early age, the burden of MS and its direct and indirect costs are significant [6].

In 2016, there were 2,221,188 MS cases in the world, representing an increase of over $10 \%$ compared with 1990 . The highest prevalence of MS was in North America, Western Europe and Australia, while the lowest rates were reported in Sub-Saharan Africa, Central Africa and Oceania [7].

The incidence and prevalence of MS in various studies have been investigated and diverse results have been reported [3,4,8-11].Also, there are considerable geographical variations in incidence of MS in Iran [12]. Based on the Eskandarieh et al study, the prevalence of MS increased from 45 per 100,000 in 2011 to 54.5 per 100,000 in 2013 in Iran [13] and in an another study they reported that the prevalence proportion in Tehran, 2014, was 101.39 per 100,000 [14] Also, in a study conducted in Isfahan in 2014, the prevalence rate was 85.8 per 100,000 [15]. In addition, familial MS cases have increased in Tehran in recent years [8, 16 ]. Based on the division of the world's regions by Kurtzke [17], Tehran is considered a high frequency areas (prevalence $\geq 30 / 100,000)$ for the MS.

According to Hosseinzadeh et al [12], Tehran is considered as one of the high-frequency provinces for MS. Since the frequency of MS in our region is high, therefore, the present study aimed to investigate the longitudinal prevalence of MS in Tehran, Iran.

\section{Methods}

This population-based study was conducted in Tehran province of Iran based on the annual report data through the Iranian MS Society (IMSS) registry system from 1st April 1999 to 31st December 2018. The registration program and its validity and reliability were described in the previous study [18]. The prevalence estimate values for MS were calculated by applicant of population data, obtained from the Statistical Centre of Iran.

The age-standardized prevalence proportion (ASP) were calculated based on years of disease onset.

The Iranian MS Society, established in 1999, is the one registry center in Tehran that comprehensively registers baseline characteristics including gender, birth date (age), age at disease onset, date of diagnosis, familial history of MS, as well as social and clinical data of MS patients. Disease diagnosis was confirmed using the latest McDonald criteria by neurologists [19].

IMSS provide extensive facilities for members and all patients were encouraged by neurologists to refer to the IMSS for registration and receiving tracking code for receiving treatment. The IMSS membership card must activate by patients to keep their presence active every 5-year To design the population based cross-sectional study, the scholar tried to cover the most important epidemiological variables, which were related at the individual level to MS recurrence including gender, birth date (age), age at disease onset, and date of diagnosis.

A trained interviewer was explained the goals of the MS registry in IMSS and inform consent was taken from all patients before disclosing study processes.

\section{Statistical Methods}

Categorical and continuous data were presented as number (percent) and mean (Standard Deviation, (S.D.)) as well as 95\% Confidence Interval (CI). To calculate familial MS prevalence, direct standardization was used to adjust the age effect by using world standard population [20].

Age standardized prevalence proportion (ASP) was calculated per 100,000 by "dstdize" command in Stata software. Excel software were used to clean the data and to depicting the graphs. The Poisson regression model was used to estimate significance of change over time for total prevalence, sex-specific prevalence and sex ratio. All analyses were performed using Stata software version 14 (Stata Corp, College Station, TX). 
To calculate prevalence proportion, the interested population was extracted from statistical center of Iran in years in which census was done (2006, 2011 and 2016); otherwise, exponential formula was used to estimate the population as below:

$$
\mathrm{P}_{\mathrm{T}}=\mathrm{P}_{0}(1+\mathrm{r})^{\mathrm{t}}
$$

Where, $\mathrm{P}_{\mathrm{T}}$ is the population to be estimated (population at time $\mathrm{T}$ ), $\mathrm{P}_{0}$ stands for population at time zero, $\mathrm{r}$ is growth rate (it was considered as 1.44 for 2007 10 and 1.72 for 2012-15 and 2017 and 2018) and t is elapsed time in years from time zero.

\section{Results}

\section{Age at disease onset and its trends}

In our population-based MS registry, totally 21,580 cases of MS were registered and included in the analysis. Out of them, $24.99 \%$ (5,393 cases) was male and $75.01 \%$ (16,187 cases) was female. The mean age of MS onset was 28.8 years (S.D: 8.7, ranged from 3-77 years). The mean age of males (29.5S.D: 8.9was significantly $(p<0.001)$ higher than female (28.6S.D: 8.6). The means age of MS onset in males and females in 2018 were 30.9 (S.D: 8.3$)$ and 31.8 (S.D: 8.9$)$, respectively. $13.4 \%$ of MS cases were familial MS. Demographic characteristics of MS cases were presented in Table 1.

Table 1

Demographic characteristics of MS cases in

Tehran, Iran

\begin{tabular}{|lll|}
\hline Variables & & $\mathbf{N}(\%)$ \\
\hline Sex & Male & $5393(24.99)$ \\
& Female & $16187(75.01)$ \\
\hline Age & $\leq 18$ & $2023(9.7)$ \\
& $19-24$ & $5098(24.7)$ \\
& $25-29$ & $4807(23.3)$ \\
& $30-34$ & $3704(18.0)$ \\
& $35-39$ & $2395(11.6)$ \\
& $40-44$ & $1518(7.4)$ \\
& $\geq 45$ & $1091(5.3)$ \\
Familial MS & Yes & $2815(13.4)$ \\
& No & $18145(86.6)$ \\
\hline
\end{tabular}

\section{Age standardized prevalence proportion of MS}

In Table 2, the crude and ASP of MS were reported by gender and year. The ASP of MS ranged from 73.7 (95\%Cl: 72.1-75.2) per 100,000 in 2006 to 137.6 (95\% Cl: 135.7-139.5) per 100,000 in 2018. The MS ASP was estimated 54.1 (95\%Cl: 53.6-54.6) per 100,000 among males and 174.5 (95\%Cl: 173.6-175.4) per 100,000 among females. The results of Poisson regression model suggested that there is a significant change over time for total prevalence $(p=0.001)$, prevalence among males $(p=0.001)$ and prevalence among females $(P=0.001)$. 
Table 2

The crude and age standardized prevalence proportion of MS in Tehran, Iran during 2006-2018

\begin{tabular}{|c|c|c|c|c|c|c|c|c|c|c|c|c|}
\hline \multirow[t]{2}{*}{ Year } & \multicolumn{4}{|l|}{ Female } & \multicolumn{4}{|l|}{ Male } & \multicolumn{4}{|l|}{ Total } \\
\hline & Population & Count & Prevalence & $\begin{array}{l}\text { ASP... } \\
(95 \% \mathrm{Cl})\end{array}$ & Population & Count & Prevalence & $\begin{array}{l}\text { ASP... } \\
(95 \% \mathrm{Cl})\end{array}$ & Population & Count & Prevalence & $\begin{array}{l}\text { ASP... } \\
(95 \% \mathrm{Cl})\end{array}$ \\
\hline 2006 & 5513872 & 6848 & 124.2 & $\begin{array}{l}115.4 \\
(112.6- \\
118.2)\end{array}$ & 5831418 & 2146 & 36.8 & $\begin{array}{l}33.9 \\
(32.4- \\
25.3)\end{array}$ & 11345290 & 8994 & 79.3 & $\begin{array}{l}73.7 \\
(72.1- \\
75.2)\end{array}$ \\
\hline 2007 & 5593267 & 7633 & 136.5 & $\begin{array}{l}126.7 \\
(123.8- \\
129.6)\end{array}$ & 5915395 & 2397 & 40.5 & $\begin{array}{l}37.2 \\
(35.7- \\
38.7)\end{array}$ & 11508662 & 10030 & 87.2 & $\begin{array}{l}80.9 \\
(79.3- \\
82.5)\end{array}$ \\
\hline 2008 & 5673810 & 8447 & 148.9 & $\begin{array}{l}137.9 \\
(134.9- \\
141.0)\end{array}$ & 6000577 & 2665 & 44.4 & $\begin{array}{l}40.9 \\
(39.3- \\
42.5)\end{array}$ & 11674387 & 11112 & 95.2 & $\begin{array}{l}88.3 \\
(86.6- \\
90.0)\end{array}$ \\
\hline 2009 & 5755513 & 9232 & 160.4 & $\begin{array}{l}148.3 \\
(145.2- \\
151.4)\end{array}$ & 6086985 & 2930 & 48.1 & $\begin{array}{l}44.3 \\
(42.7- \\
45.9)\end{array}$ & 11842498 & 12162 & 102.7 & $\begin{array}{l}95.1 \\
(93.4- \\
96.8)\end{array}$ \\
\hline 2010 & 5838393 & 10160 & 174.0 & $\begin{array}{l}160.6 \\
(157.4- \\
163.8)\end{array}$ & 6174637 & 3198 & 51.8 & $\begin{array}{l}47.7 \\
(46.0- \\
49.3)\end{array}$ & 12013030 & 13358 & 111.2 & $\begin{array}{l}102.8 \\
(101.0- \\
104.6)\end{array}$ \\
\hline 2011 & 6045398 & 11187 & 185.1 & $\begin{array}{l}170.2 \\
(167.0- \\
173.4)\end{array}$ & 6137993 & 3513 & 57.2 & $\begin{array}{l}52.4 \\
(50.6- \\
54.2)\end{array}$ & 12183391 & 14700 & 120.7 & $\begin{array}{l}111.2 \\
(109.3- \\
113.0)\end{array}$ \\
\hline 2012 & 6149379 & 12028 & 195.6 & $\begin{array}{l}179.4 \\
(176.1- \\
182.7)\end{array}$ & 6243566 & 3780 & 60.6 & $\begin{array}{l}55.3 \\
(53.5- \\
57.1)\end{array}$ & 12392945 & 15808 & 127.6 & $\begin{array}{l}117.2 \\
(115.4- \\
119.1)\end{array}$ \\
\hline 2013 & 6255149 & 12867 & 205.7 & $\begin{array}{l}188.2 \\
(184.9- \\
191.5)\end{array}$ & 6350955 & 4083 & 64.3 & $\begin{array}{l}58.7 \\
(56.8- \\
60.5)\end{array}$ & 12606104 & 16950 & 134.5 & $\begin{array}{l}123.3 \\
(121.4- \\
125.2)\end{array}$ \\
\hline 2014 & 6362737 & 13583 & 213.5 & $\begin{array}{l}194.9 \\
(191.5- \\
198.2)\end{array}$ & 6460192 & 4357 & 67.5 & $\begin{array}{l}61.4 \\
(59.6- \\
63.3)\end{array}$ & 12822929 & 17940 & 139.9 & $\begin{array}{l}128.0 \\
(126.1- \\
129.9)\end{array}$ \\
\hline 2015 & 6472176 & 14211 & 219.6 & $\begin{array}{l}200.0 \\
(196.7- \\
203.4)\end{array}$ & 6571307 & 4591 & 69.9 & $\begin{array}{l}63.6 \\
(61.7- \\
65.4)\end{array}$ & 13043483 & 18802 & 144.2 & $\begin{array}{l}131.6 \\
(129.7- \\
133.6)\end{array}$ \\
\hline 2016 & 6593965 & 14875 & 225.6 & $\begin{array}{l}205.0 \\
(201.7- \\
208.4)\end{array}$ & 6673672 & 4828 & 72.3 & $\begin{array}{l}65.7 \\
(63.8- \\
67.6)\end{array}$ & 13267637 & 19703 & 148.5 & $\begin{array}{l}135.3 \\
(133.4- \\
137.3)\end{array}$ \\
\hline 2017 & 6693000 & 15304 & 228.7 & $\begin{array}{l}207.6 \\
(204.2- \\
210.9)\end{array}$ & 6768000 & 5037 & 74.4 & $\begin{array}{l}67.5 \\
(65.6- \\
69.4)\end{array}$ & 13461000 & 20341 & 151.1 & $\begin{array}{l}137.5 \\
(135.6- \\
139.5)\end{array}$ \\
\hline 2018 & 6784000 & 15505 & 228.6 & $\begin{array}{l}207.3 \\
(204.0- \\
210.7)\end{array}$ & 6853000 & 5131 & 74.9 & $\begin{array}{l}67.9 \\
(66.0- \\
69.8)\end{array}$ & 13636000 & 20636 & 151.3 & $\begin{array}{l}137.6 \\
(135.7- \\
139.5)\end{array}$ \\
\hline Total & - & - & 190.5 & $\begin{array}{l}174.5 \\
(173.6- \\
175.4)\end{array}$ & - & - & 59.3 & $\begin{array}{l}54.1 \\
(53.6- \\
54.6)\end{array}$ & - & - & - & - \\
\hline
\end{tabular}

The results showed that the MS prevalence among females were remarkably higher than males in all years. However, we provided sex-specific prevalence data (count, population, prevalence) over study period in Table 2.

\section{Sex ratio trends}

The MS sex ratios over the 13-year study period were displayed in Fig. 1 and it decreased from 3.7 (in 2010) to 2.06 (in 2017 ) and its trend was decreasing and also there is no notable difference among crude and age-standardized sex ratio. The results of Poisson regression model revealed that there is a significant change over time for sex ratio $(p=0.001)$,

\section{Discussion}

The current study examined the trend of MS prevalence in Capital of Iran, Tehran, from 2006 till 2018.The results of this study suggested that the prevalence of MS in Tehran is growing, and unadjusted prevalence proportion has increased from 79.3 cases in 2006 to 151.7 cases (per 100,000) in 2018 and also agestandardized prevalence proportion has increased from 73.7 cases in 2006 to 137.6 cases (per 100,000) in 2018. 
Therefore, According to the global divisions [17], Tehran is considered as a region with high prevalence (prevalence $\geq 30 / 100,000)$ and the prevalence of MS in Tehran is the highest in Asia and among Middle Eastern countries [13]. In addition, the results revealed that the time trend of age standardized MS female to male sex ratio in recent years has been declining and it has fallen to 2.14 in 2018 .

According to Wallin MT et al study [3] in United States in 2010, the prevalence of MS in the population over 18 years, cumulated over 10 years was 309.2 per 100,000 and the highest prevalence was in the 55- to 64-year age group. Compared to our study findings which most cases were observed in the age group below 40 years, it has a higher prevalence and different age distribution. When coupled with prior estimates of MS prevalence in Iran, it seems that there has been a relatively increase during the last decades. In Eskandarieh et al study [4] in Tehran, the MS prevalence was 101.39 per 100000 in 2014 and ageadjusted prevalence proportion were 134 and 42.5 for females and males respectively. In another review study, MS prevalence for Iran in 2013 was 85.8 per $100,000[13]$.

According to Hosseinzadeh et al [12], Tehran is considered as one of the high-frequency provinces for MS. It sounds that the high MS frequency in Tehran may be related to the level of urbanization, their social and economic status and air pollution.

On the other hand, better access to health services can play an important role, which in turn leads to better diagnosis and cases registration.

Tehran is known as one of the most polluted cities in the world [21]. Although some studies have not reported a significant association between air pollution markers $\left(\mathrm{PM}_{2.5}, \mathrm{NO}_{2}\right.$, and $\left.\mathrm{O}_{3}\right)$ and $\mathrm{MS}$ [22], several studies had shown some evidences that air pollution can have a significant relationship with the incidence and recurrence of MS [23-25].

The possible association between air pollution and MS incidence and recurrence has been justified through several mechanisms, most likely being that air pollution leads to vitamin D deficiency, excessive free radical production, inflammatory factors expression, induction of chronic inflammation, mitochondrial dysfunction, and increased oxidative stress, which can be linked to MS incidence and recurrence [24, 25].

One issue that has been shown in most studies is that women are more susceptible to MS than men [26, 27]. In a relatively large study on Canadian patients with MS, sex ratio was estimated 3.2, which is so similar to our result [26]. Also, it has been reported as 3.06 in Eskandarieh et al study [8]. In a study conducted in Turkey [28], the prevalence of MS in Karabük and Akçakoca were 95.9 and 46.1 per 100,000 and the prevalence of MS in the Middle East and north Africa was 51.52 cases per 100,000 [29]. The estimated prevalence proportion in our study revealed that MS is more prevalent in Tehran in compared to the Middle East countries.

It should be noted that the trend of sex ratio in our study was somewhat declining (from 3.20 in 2006 to 2.14 in 2018). However, some studies have reported an increase in this trend [30,31], However, no significant trend was observed in a study in Sweden [32].

In terms of age groups, in our study, nearly $60 \%$ of cases were diagnosed before age 30 years. Other similar studies have also shown a higher incidence of disease at an early age $[4,5]$. The disease onset in the early age leads to an increase in the number of years lived with disability (YLDs) and eventually to a Disability-adjusted life years (DALYs) [33-35].

There are some limitations and strengths to our study. Because the province of Tehran is both large in population and geographical area, and MS registration is elective, the MS registration may be incomplete and some cases may not be registered. Therefore, the obtained prevalence proportion maybe is underestimated. On the other hand, it should be highlighted that IMSS registration facilitates access to health care and services for patients. This is a strong inducement that likely facilitates registration and retention and thus, it is considered as study strengthens.

\section{Conclusion}

Our finding suggested that the prevalence proportion of MS in Tehran province is relatively high and disease occurrence is more common in the under-40 age group than in the older ones. The results suggested that the prevalence of the MS was higher in women, and the trend of female to male sex ratio in study period has been declining.

\section{Abbreviations}

\section{MS}

Multiple Sclerosis,

IMSS

Iranian MS Society

$\mathrm{Cl}$

Confidence Interval

S.D

Standard Deviation

ASP

Age Standardized Prevalence

\section{Declarations}


Ethics approval and consent to participate: The study was approved ethically by institutional review board of Tehran University of Medical Sciences. An informed consent was obtained from each participant. In the study, the privacy of the participants was maintained.

Consent for publication: Not Applicable.

Availability of data and materials: The datasets used and analysed during the study available from the corresponding author on reasonable request.

Competing interests: The authors declare no competing interests.

Funding: This study was funded by Tehran University of Medical Sciences (TUMS). The founder had no role in the design of the study and collection, analysis, and interpretation of data and in the manuscript preparation.

Authors' contributions: MAS conceived and designed the study, and data collection was done by SE. Data analysis and interpretation was done by AAH and SE. The manuscript was drafted by AAH and SE and critically revised by MAS. All authors read and approved the final version of manuscript.

Acknowledgments: We would like to thank for research grant of Tehran University of medical sciences, code 40376-188-01-98.

\section{References}

1. García-Domínguez JM, Maurino J, Martínez-Ginés ML, Carmona O, Caminero AB, Medrano N, et al. Economic burden of multiple sclerosis in a population with low physical disability. BMC public health. 2019;19 1:609; doi: 10.1186/s12889-019-6907-x.

2. Stenager E. A global perspective on the burden of multiple sclerosis. The Lancet Neurology. 2019;18 3:227-8; doi: 10.1016/S1474-4422(18)30498-8.

3. Wallin MT, Culpepper WJ, Campbell JD, Nelson LM, Langer-Gould A, Marrie RA, et al. The prevalence of MS in the United States: A population-based estimate using health claims data. Neurology. 2019;92 10:e1029-e40; doi: 10.1212/wnl.0000000000007035.

4. Eskandarieh S, Heydarpour P, Elhami SR, Sahraian MA. Prevalence and Incidence of Multiple Sclerosis in Tehran, Iran. Iranian journal of public health. 2017;46 5:699-704.

5. Greer JM, McCombe PA. Role of gender in multiple sclerosis: clinical effects and potential molecular mechanisms. Journal of neuroimmunology. 2011;234 1-2:7-18; doi: 10.1016/j.jneuroim.2011.03.003.

6. Naci H, Fleurence R, Birt J, Duhig A. Economic burden of multiple sclerosis: a systematic review of the literature. PharmacoEconomics. 2010;28 5:363-79; doi: 10.2165/11532230-000000000-00000.

7. Wallin MT, Culpepper WJ, Nichols E, Bhutta ZA, Gebrehiwot TT, Hay SI, et al. Global, regional, and national burden of multiple sclerosis 1990-2016: a systematic analysis for the Global Burden of Disease Study 2016. The Lancet Neurology. 2019;18 3:269-85; doi: 10.1016/S1474-4422(18)30443-5.

8. Eskandarieh S, Allahabadi NS, Sadeghi M, Sahraian MA. Increasing prevalence of familial recurrence of multiple sclerosis in Iran: a population based study of Tehran registry 1999-2015. BMC neurology. 2018;18 1:15; doi: 10.1186/s12883-018-1019-2.

9. Al-Sakran LH, Marrie RA, Blackburn DF, Knox KB, Evans CD. Establishing the Incidence and Prevalence of Multiple Sclerosis in Saskatchewan. The Canadian journal of neurological sciences Le journal canadien des sciences neurologiques. 2018;45 3:295-303; doi: 10.1017/cjn.2017.301.

10. Marrie RA, O'Mahony J, Maxwell C, Ling V, Yeh EA, Arnold DL, et al. Incidence and prevalence of MS in children: A population-based study in Ontario, Canada. Neurology. 2018;91 17:e1579-e90; doi: 10.1212/wnl.0000000000006395.

11. Harirchian MH, Fatehi F, Sarraf P, Honarvar NM, Bitarafan S. Worldwide prevalence of familial multiple sclerosis: A systematic review and meta-analysis. Multiple sclerosis and related disorders. 2018;20:43-7; doi: 10.1016/j.msard.2017.12.015.

12. Hosseinzadeh A, Baneshi MR, Sedighi B, Kermanchi J, Haghdoost AA. Geographic variations of multiple sclerosis in Iran: A population based study. Multiple sclerosis and related disorders. 2019;28:244-9; doi: 10.1016/j.msard.2019.01.001.

13. Eskandarieh S, Heydarpour P, Minagar A, Pourmand S, Sahraian MA. Multiple Sclerosis Epidemiology in East Asia, South East Asia and South Asia: A Systematic Review. Neuroepidemiology. 2016;46 3:209-21; doi: 10.1159/000444019.

14. Eskandarieh S, Heydarpour P, Elhami S-R, Sahraian MA. Prevalence and Incidence of Multiple Sclerosis in Tehran, Iran. Iranian journal of public health. 2017;46 5:699-704.

15. Etemadifar M, Abtahi SH, Akbari M, Murray RT, Ramagopalan SV, Fereidan-Esfahani M. Multiple sclerosis in Isfahan, Iran: an update. Multiple sclerosis (Houndmills, Basingstoke, England). 2014;20 8:1145-7; doi: 10.1177/1352458513516531.

16. Eskandarieh S, Molazadeh N, Moghadasi AN, Azimi AR, Sahraian MA. The prevalence, incidence and familial recurrence of multiple sclerosis in Tehran, Iran. Multiple sclerosis and related disorders. 2018;25:143; doi: 10.1016/j.msard.2018.07.023.

17. Kurtzke JF. Multiple sclerosis in time and space--geographic clues to cause. Journal of neurovirology. 2000;6 Suppl 2:S134-40.

18. Shahin S, Eskandarieh S, Moghadasi AN, Razazian N, Baghbanian SM, Ashtari F, et al. Multiple sclerosis national registry system in Iran: Validity and reliability of a minimum data set. Multiple sclerosis and related disorders. 2019;33:158-61; doi: 10.1016/j.msard.2019.06.009.

19. Hartung HP, Graf J, Aktas O, Mares J, Barnett MH. Diagnosis of multiple sclerosis: revisions of the McDonald criteria 2017 - continuity and change. Current opinion in neurology. 2019;32 3:327-37; doi: 10.1097/wco.0000000000000699.

20. National Institutes of Health. Standard Populations - 19 Age Groups. https://seer.cancer.gov/stdpopulations/stdpop.19ages.html (2019). Accessed July 2019.

21. Jamaati H, Attarchi M, Hassani S, Farid E, Seyedmehdi SM, Pormehr PS. Investigating air quality status and air pollutant trends over the Metropolitan Area of Tehran, Iran over the past decade between 2005 and 2014. Environ Health Toxicol. 2018;33 2:e2018010-e; doi: 10.5620/eht.e2018010. 
22. Bai L, Burnett RT, Kwong JC, Hystad P, van Donkelaar A, Brook JR, et al. Long-term exposure to air pollution and the incidence of multiple sclerosis: $A$ population-based cohort study. Environmental research. 2018;166:437-43; doi: 10.1016/j.envres.2018.06.003.

23. Mehrpour M, Shams-Hosseini NS, Rezaali S, Sahraiian MA, Taki S. Effect of Air Pollutant Markers on Multiple Sclerosis Relapses. Iranian journal of public health. 2013;42 10:1167-73.

24. Esmaeil Mousavi S, Heydarpour P, Reis J, Amiri M, Sahraian MA. Multiple sclerosis and air pollution exposure: Mechanisms toward brain autoimmunity. Medical Hypotheses. 2017;100:23-30; doi: https://doi.org/10.1016/j.mehy.2017.01.003.

25. Ashtari F, Esmaeil N, Mansourian M, Poursafa P, Mirmosayyeb O, Barzegar M, et al. An 8-year study of people with multiple sclerosis in Isfahan, Iran: Association between environmental air pollutants and severity of disease. Journal of neuroimmunology. 2018;319:106-11; doi: 10.1016/j.jneuroim.2018.02.019.

26. Orton S-M, Herrera BM, Yee IM, Valdar W, Ramagopalan SV, Sadovnick AD, et al. Sex ratio of multiple sclerosis in Canada: a longitudinal study. The Lancet Neurology. 2006;5 11:932-6; doi: https://doi.org/10.1016/S1474-4422(06)70581-6.

27. Koch-Henriksen N, Sorensen PS. The changing demographic pattern of multiple sclerosis epidemiology. Lancet Neurol. 2010;9 5:520-32; doi: $10.1016 / \mathrm{s} 1474-4422(10) 70064-8$

28. Börü ÜT, Bilgiç AB, Köseoğlu Toksoy C, Yılmaz AY, Tasdemir M, Sensöz NP, et al. Prevalence of Multiple Sclerosis in a Turkish City Bordering an Iron and Steel Factory. J Clin Neurol. 2018;14 2:234-41; doi: 10.3988/jcn.2018.14.2.234.

29. Heydarpour P, Khoshkish S, Abtahi S, Moradi-Lakeh M, Sahraian MA. Multiple Sclerosis Epidemiology in Middle East and North Africa: A Systematic Review and Meta-Analysis. Neuroepidemiology. 2015;44 4:232-44; doi: 10.1159/000431042.

30. Trojano M, Lucchese G, Graziano G, Taylor BV, Simpson S, Jr., Lepore V, et al. Geographical variations in sex ratio trends over time in multiple sclerosis. PloS one. 2012;7 10:e48078-e; doi: 10.1371/journal.pone.0048078.

31. Holmberg M, Murtonen A, Elovaara I, Sumelahti M-L. Increased Female MS Incidence and Differences in Gender-Specific Risk in Medium- and High-Risk Regions in Finland from 1981-2010. Multiple Sclerosis International. 2013;2013:6; doi: 10.1155/2013/182516.

32. Bostrom I, Stawiarz L, Landtblom AM. Sex ratio of multiple sclerosis in the National Swedish MS Register (SMSreg). Multiple sclerosis (Houndmills, Basingstoke, England). 2013;19 1:46-52; doi: 10.1177/1352458512446169.

33. Chung S-E, Cheong H-K, Park J-H, Kim HJ. Burden of disease of multiple sclerosis in Korea. Epidemiology and health. 2012;34:e2012008-e; doi: 10.4178/epih/e2012008.

34. Wallin MT, Culpepper WJ, Nichols E, Bhutta ZA, Gebrehiwot TT, Hay SI, et al. Global, regional, and national burden of multiple sclerosis 1990\&\#x2013;2016: a systematic analysis for the Global Burden of Disease Study 2016. The Lancet Neurology. 2019;18 3:269-85; doi: 10.1016/S14744422(18)30443-5.

35. Mansouri S, Zayeri F. Global and Regional Trends of Multiple Sclerosis Disability-Adjusted Life Years Rates: A 25-Year Assessment. Neuroepidemiology. 2019;52 1-2:17-24; doi: 10.1159/000492819.

\section{Figures}

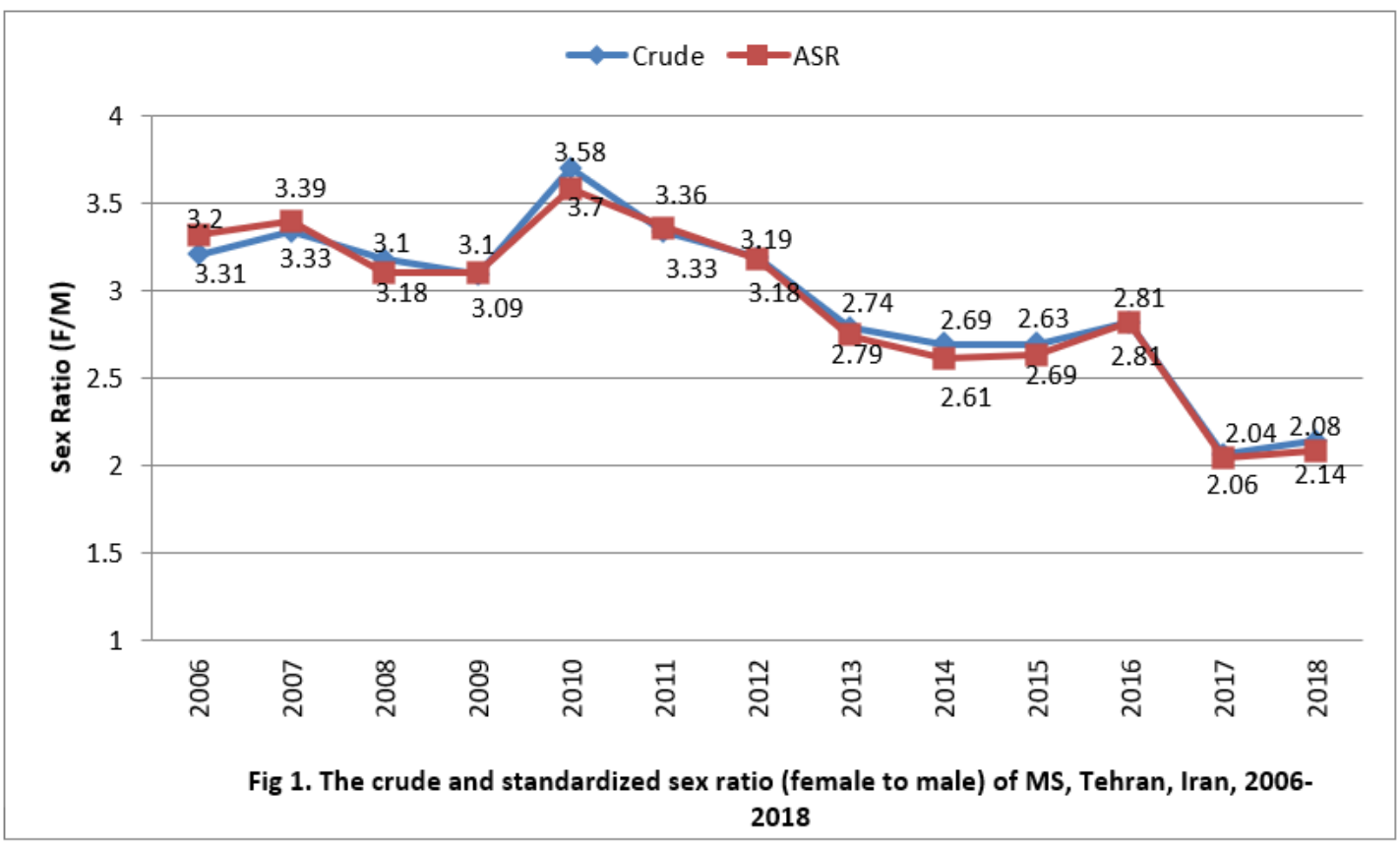

Figure 1 
The crude and standardized sex ratio (female to male) of MS, Tehran, Iran, 2006-2018

Page $8 / 8$ 